\title{
Suppression of keloid fibroblast
}

\author{
Viroj Wiwanitkit
}

Received: 9 November 2010 / Accepted: 11 November 2010 / Published online: 24 November 2010

(C) Springer-Verlag 2010

Editor, I read the recent publication on production of extracellular matrix (ECM) in the keloid fibroblast (KF) cells with a great interest [1]. Hsu et al. [1] concluded that "excessive production of ECM in the KF cells could be blocked and/or rapidly decreased by curcumin." Indeed, the used of curcuminoids from local plants has been mentioned as an ethnopharmacological agent for years. Phan et al. [3] presented the efficacy of using several compounds including curcumin for reduction of scar. However, in this report, curcumin was inferior to quercetin [3]. For implication of using curcumin in keloid treatment, the in vivo biological process that might deform the curcumin and reduce the therapeutic efficacy should be kept in mind. In addition, the contact dermatitis to curcumin can also be seen in medical practice [2].

\section{References}

1. Hsu CY, Chen MJ, Yu YM, Ko SY, Chang CC (2010) Suppression of TGF- $\beta 1 /$ SMAD pathway and extracellular matrix production in primary keloid fibroblasts by curcuminoids: its potential therapeutic use in the chemoprevention of keloid. Arch Dermatol Res 302(10):717-724

2. Liddle M, Hull C, Liu C, Powell D (2006) Contact urticaria from curcumin. Dermatitis 17(4):196-197

3. Phan TT, Sun L, Bay BH, Chan SY, Lee ST (2003) Dietary compounds inhibit proliferation and contraction of keloid and hypertrophic scar-derived fibroblasts in vitro: therapeutic implication for excessive scarring. J Trauma 54(6):1212-1224

V. Wiwanitkit $(\square)$

Wiwanitkit House, Bangkhae,

Bangkok 10160, Thailand

e-mail:wviroj@yahoo.com 